\title{
Lymphoepithelioma-Like Carcinoma in Liver
}

\author{
Ismail Labgaa, ${ }^{{ }^{\dagger}}$ Ashley Stueck, ${ }^{\ddagger}$ and Stephen C. Ward
}

From the Division of Liver Diseases* and the Department of Pathology, ${ }^{\S}$ Icahn School of Medicine at Mount Sinai, New York, New York; the Department of Visceral Surgery, ${ }^{\dagger}$ Lausanne University Hospital CHUV, Lausanne, Switzerland; and the Department of Pathology, ${ }^{\ddagger}$ Dalhousie University, Halifax, Nova Scotia, Canada

Accepted for publication

February 27, 2017.

Address correspondence to Stephen C. Ward, M.D., Ph.D.,

Department of Pathology, Icahn

School of Medicine at Mount

Sinai, One Gustave L. Levy

Place, Box 1194, New York,

NY 10029. E-mail: stephen.

ward@mountsinai.org.

\begin{abstract}
Liver cancer, primarily encompassing hepatocellular carcinoma and intrahepatic cholangiocarcinoma, has become the second leading cause of worldwide cancer-related death during the past two decades. Lymphoepithelioma-like carcinomas (LELCS) are defined as tumors composed of undifferentiated epithelial cells with a prominent lymphoid infiltrate, and can arise in the liver as hepatocellular or cholangiocarcinoma forms. Patients with liver LELC display distinctive demographics and tumor characteristics. LELCs also appear to be associated with strikingly better outcomes compared to typical liver cancers, with 5 -year survival rates of $57 \%$ to $100 \%$ versus $12 \%$ to $68 \%$, respectively. Liver LELCs represent a unique model of immune response in liver cancer. Data on LELCs of the liver remain limited, and future comprehensive studies are needed to further elucidate this disease, which could ultimately offer precious insights for immunotherapeutic strategies in liver cancer. (Am J Pathol 2017, 187: 1438-1444; http:// dx.doi.org/10.1016/j.ajpath.2017.02.022)
\end{abstract}

Liver cancer is now the fifth leading cause of cancer incidence in males, worldwide. ${ }^{1}$ Associated with dismal outcomes, its 5-year survival rate is only $16 \%$ in the United States, making it the most aggressive malignancy after pancreatic cancer. ${ }^{2}$ During the past 20 years, the number of deaths caused by liver cancer has doubled, and it is now the second leading cause of cancer-related death in the world. ${ }^{3}$ As a consequence, liver cancer has dramatically become the leading cause of increasing mortality in the United States during the past two decades. ${ }^{4}$

Most primary liver cancer is composed by hepatocellular carcinoma (HCC) and intrahepatic cholangiocarcinoma (iCC). Both tumor types are associated with low survival rates because of their biological aggressiveness, but also because most patients are diagnosed at advanced stages, when therapeutic options remain limited. Substantial efforts have been pursued to better characterize these tumors, on both pathological and genomic levels, allowing the identification of distinctive molecular subclasses. However, these advances have not yet been translated into clinical practice to guide decision making for the management of liver cancer.

Originally described in the nasopharynx, lymphoepithelioma-like carcinoma (LELC) is defined as a tumor composed of undifferentiated epithelial cells with a prominent lymphoid infiltrate. Cases were subsequently reported in many other organs, including in liver. ${ }^{5}$ Hepatic cases of LELC have been observed for both HCC and iCC, and were further designated lymphoepithelioma-like hepatocellular carcinoma (LEL-HCC) and lymphoepitheliomalike cholangiocarcinoma (LEL-CC), respectively. LELC of the liver is a relatively rare finding, but the number of reported cases has strikingly increased during the past few years (Figure 1), with data suggesting that this entity may have been underestimated or underrecognized. Not only of great interest for their epidemiological and pathological features, liver LELCs are also associated with markedly better outcomes than typical HCC and iCC. Hepatic LELCs represent a unique model of immune response against liver cancer that may be related to survival benefits, and this deserves further study. This is therefore of particular pertinence, especially when considering the expanding role of immunotherapy in cancer treatment.

Supported by a Swiss National Science Foundation grant P2LAP3_164927 (I.L.) the Foundation Roberto \& Gianna Gonella (I.L.), and Foundation SICPA (I.L.).

Disclosures: None declared. 


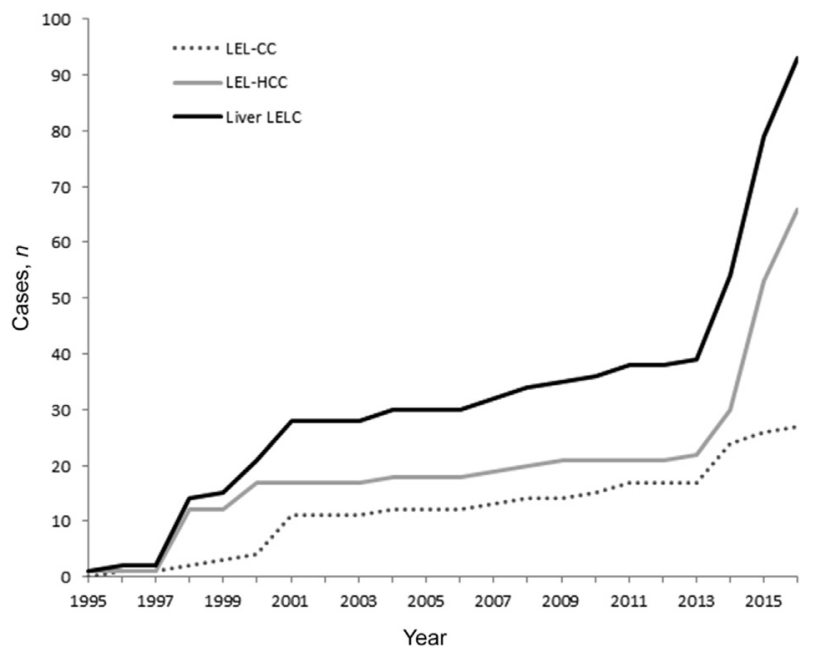

Figure 1 Number of reported cases of hepatic lymphoepithelioma-like carcinoma (LELC). Number of cases reported in the English literature since 1995, for lymphoepithelioma-like hepatocellular carcinoma (LEL-HCC), lymphoepithelioma-like cholangiocarcinoma (LEL-CC), and both types.

This review aims to provide a comprehensive overview of the available data on hepatic LELC from epidemiological, clinical, pathological, and research perspectives.

\section{LEL-HCC}

To date, 66 cases of LEL-HCC have been reported and are detailed in Table 1. Available demographics of the patients and features of the tumors are displayed in Table 2. Overall, patients were mostly males (64\%), with a median age of 58 years (Figure 2A). Sixty-five percent of patients were white, whereas $30 \%$ were Asian. The underlying liver was cirrhotic in $46 \%$ of the cases, with hepatitis B virus and hepatitis $C$ virus being the underlying cause in $40 \%$ and $34 \%$, respectively. Most patients had early-stage HCC, with most single lesions (88\%), a median size of $38 \mathrm{~mm}$, and $86 \%$ falling within Barcelona Clinic Liver Cancer Group Stage 0-A. Most patients underwent surgical resection [59/65 (91\%)], whereas the remaining six LEL-HCC had orthotopic liver transplant.

From a pathological standpoint, tumors were grossly well circumscribed, gray-yellow-white and soft, with variable encapsulation. ${ }^{6-10}$ Histologically, the carcinoma was poorly differentiated, composed of atypical cells with syncytial cytoplasm and nuclei with prominent nucleoli, and infiltrated by abundant lymphocytes (Figure 3A). The dense lymphocytic infiltrate distinguishes LEL-HCC from typical poorly differentiated HCC (Figure 3B). In 1998, Wada et al ${ }^{11}$ proposed using a cutoff of $>100$ tumor-infiltrating lymphocytes in 10 high-power fields to quantitatively define LEL-HCC.

Table 1 Reported Cases of LEL-HCC

\begin{tabular}{|c|c|c|c|c|c|c|c|c|c|c|c|c|c|c|c|}
\hline Reference & Sex & $\begin{array}{l}\text { Age, } \\
\text { years }\end{array}$ & Race & $\mathrm{HBV}^{+}$ & $\mathrm{HCV}^{+}$ & $\mathrm{EBV}^{+}$ & Cirrhosis & $\begin{array}{l}\text { AFP } \\
(>20 \mu \mathrm{g} / \mathrm{L})\end{array}$ & $\begin{array}{l}\mathrm{BCLC} \\
(0 / \mathrm{A})\end{array}$ & $\begin{array}{l}\text { No. of } \\
\text { lesions }\end{array}$ & $\begin{array}{l}\text { Size, } \\
\mathrm{mm}\end{array}$ & $\begin{array}{l}\text { Vascular } \\
\text { invasion }\end{array}$ & Treatment & $\begin{array}{l}\text { FU, } \\
\text { months }\end{array}$ & Outcomes \\
\hline An et $\mathrm{al}^{6}$ & M & 50 & Asian & - & + & - & + & + & - & 1 & 35 & + & LR & 6 & AWD \\
\hline Chen et $\mathrm{al}^{7}$ & $M$ & 56 & Asian & - & + & - & + & + & + & 1 & 32 & - & LR & 21 & DOD \\
\hline Cacciato Insilla et $\mathrm{al}^{8}$ & $\mathrm{~F}$ & 81 & NA & - & + & - & - & + & + & 1 & 72 & NA & LR & 15 & AWOD \\
\hline Shinoda et $\mathrm{al}^{9}$ & $M$ & 79 & Asian & - & - & - & - & + & + & 1 & 42 & - & LR & 20 & NA \\
\hline Wei et $\mathrm{al}^{10}$ & $\mathrm{~F}$ & 42 & Asian & - & - & - & & + & + & 1 & 46 & NA & LR & 8 & AWOD \\
\hline Wada et $\mathrm{al}^{11}$ & $10 \mathrm{M} / 1 \mathrm{~F}$ & 62 & NA & $0 / 11$ & $11 / 11$ & NA & $6 / 11$ & NA & NA & NA & 22 & $1+/ 11$ & LR & 5-y survi & ival: $100 \%$ \\
\hline Park et $\mathrm{al}^{12}$ & M & 57 & Asian & + & - & - & + & - & + & 1 & 27 & NA & NA & 60 & AWOD \\
\hline \multirow[t]{5}{*}{ Emile et $\mathrm{al}^{13}$} & M & 50 & White & + & + & - & + & - & + & 1 & 40 & - & OLT & 120 & AWOD \\
\hline & M & 54 & White & - & - & - & - & - & + & Multifocal & 20 & - & OLT & 92 & DOD \\
\hline & M & 59 & White & + & + & - & + & - & - & Multifocal & 50 & - & OLT & 96 & AWOD \\
\hline & M & 45 & White & - & + & - & + & - & + & 1 & 20 & - & OLT & 56 & AWD \\
\hline & M & 64 & White & - & - & - & + & - & - & Multifocal & 40 & + & OLT & 36 & AWOD \\
\hline Si et $\mathrm{al}^{14}$ & $\mathrm{~F}$ & 39 & Latino & - & + & + & + & & + & 1 & 10 & + & OLT & 5 & POD \\
\hline Nemolato et $\mathrm{al}^{15}$ & $\mathrm{~F}$ & 47 & NA & - & - & - & - & & + & 1 & 22 & NA & LR & 15 & AWOD \\
\hline Shirabe et $\mathrm{al}^{16}$ & $\mathrm{~F}$ & 58 & Asian & + & - & NA & + & + & + & 1 & 22 & NA & LR & 78 & AWOD \\
\hline \multirow[t]{8}{*}{ Patel et $\mathrm{al}^{17}$} & $\mathrm{~F}$ & 74 & White & - & - & - & - & - & - & Multifocal & 65 & + & LR & 24 & DOD \\
\hline & $M$ & 65 & White & - & - & - & - & - & + & 1 & 48 & - & LR & 60 & UD \\
\hline & $\mathrm{F}$ & 65 & White & - & - & - & - & + & + & 1 & 13 & - & LR & 108 & AWOD \\
\hline & $\mathrm{F}$ & 70 & White & - & - & - & - & + & + & 1 & 27 & - & LR & 72 & AWOD \\
\hline & $F$ & 61 & White & - & - & - & - & - & - & Multifocal & 95 & + & LR & 4 & UD \\
\hline & M & 78 & White & - & - & - & - & - & + & 1 & 105 & + & LR & 48 & AWD \\
\hline & $\mathrm{F}$ & 78 & White & - & - & - & - & - & + & 1 & 60 & - & LR & 24 & AWOD \\
\hline & $\mathrm{F}$ & 57 & White & - & - & - & - & - & - & 1 & 130 & + & LR & 1 & UD \\
\hline Chan et $\mathrm{al}^{18}$ & $13 \mathrm{M} / 7 \mathrm{~F}$ & 58 & NA & $17 / 20$ & 0 & 0 & $8+/ 20$ & $13 / 20$ & $20+/ 20$ & 1 & 38 & $\begin{array}{l}15 \% \text { micro; } \\
10 \% \text { macro }\end{array}$ & LR & 5-y surv & vival: $88 \%$ \\
\hline
\end{tabular}

Calderaro $\mathrm{J}$ et $\mathrm{al}^{19}$ reported 13 cases of LEL-HCC as part of a larger cohort of patients undergoing liver resection for HCC, but no further information regarding this subset of patients was provided.

F, female; M, male; +, positive; -, negative; AFP, $\alpha$-fetoprotein; AWD, alive with disease; AWOD, alive without disease; BCLC, Barcelona Clinic Liver Cancer Group Stage; DOD, died of disease; EBV, Epstein-Barr virus; FU, follow-up; HBV, hepatitis B virus; HCV, hepatitis C virus; LEL-HCC, lymphoepithelioma-like hepatocellular carcinoma; LR, liver resection; NA, not available; OLT, orthotopic liver transplant; POD, postoperative death; UD, unrelated death. 
Table 2 Patient Demographics and Tumor Characteristics

\begin{tabular}{lcc}
\hline Variable & LEL-HCC $(n=66)$ & LEL-CC $(n=27)$ \\
\hline Sex, male & $34 / 53(64)$ & $9 / 27(33)$ \\
Median age, years (range) & $58(58-62)$ & $57(46-64)$ \\
Race & & \\
$\quad$ White & $13 / 20(65)$ & $2 / 24(8)$ \\
$\quad$ Asian & $6 / 20(30)$ & $22 / 24(92)$ \\
$\mathrm{HBV}^{+}$ & $21 / 53(40)$ & $8 / 27(30)$ \\
$\mathrm{HCV}^{+}$ & $18 / 53(34)$ & $2 / 27(7)$ \\
$\mathrm{EBV}^{+}$ & $1 / 41(2)$ & $20 / 27(74)$ \\
Cirrhosis & $24 / 52(46)$ & $5 / 27(19)$ \\
AFP, $>$ 20 ng/L & $20 / 40(50)$ & $\mathrm{NA}$ \\
BCLC stage, 0/A & $36 / 42(86)$ & $\mathrm{NA}$ \\
Single lesion & $37 / 42(88)$ & $24 / 27(86)$ \\
Median size, mm (range) & $38(22-38)$ & $40(30-60)$ \\
Treatment & & \\
$\quad$ Transplant & $6 / 65(9)$ & $0 / 23(0)$ \\
$\quad$ Resection & $59 / 65(91)$ & $24 / 24(100)$ \\
\hline
\end{tabular}

Data are given as number/total (percentage) unless otherwise indicated. AFP, $\alpha$-fetoprotein; BCLC, Barcelona Clinic Liver Cancer Group Stage; EBV, Epstein-Barr virus; HBV, hepatitis B virus; HCV, hepatitis C virus; LEL-CC, lymphoepithelioma-like cholangiocarcinoma; LEL-HCC, lymphoepithelioma-like hepatocellular carcinoma; NA, not available.

Of note, LEL-HCC was subsequently acknowledged by the World Health Organization as a distinctive variant of HCC "with pleomorphic tumor cells intermixed with numerous lymphocytes," but clear cutoffs for number of lymphocytes is not provided. ${ }^{20}$ A few cases of LEL-HCC had well to moderately differentiated components, but the dense lymphocytic infiltrate was constant, ${ }^{11,12}$ which is in contrast to the LEL-CC, in which non-lymphoepithelioma-like carcinoma has been frequently noted concurrently. A summary of immunohistochemical expression patterns in the carcinomatous component is shown in Table 3. The carcinoma component expresses pankeratin (eg, AE1/AE3), 6,8,10,13,14 low-molecular-weight keratin (eg, K8/18), ${ }^{8,10}$ epithelial membrane antigen, ${ }^{10}$ and HepPar-1. ${ }^{7-9,12,14-16}$ Glypican-3 was expressed when tested in two cases. ${ }^{10,13}$ There may be focal expression of $\mathrm{K} 19,{ }^{6,7,17} \mathrm{~K} 7,{ }^{7} \mathrm{~K} 20,{ }^{6}$ and polyclonal carcinoembryonic antigen (canalicular pattern). ${ }^{8,17}$ p16 was expressed in three of eight cases tested; human papilloma virus was not identified by in situ hybridization (ISH) ${ }^{17}$ Only one case was assessed for p53, and wild-type expression was found. ${ }^{12}$ In the infiltrating lymphocyte population, most cells were CD3-positive T cells, with focal CD20-positive B cells noted. $^{7-14,16-18}$ The T-cell population was predominantly CD8 positive, ${ }^{9-12,17,18}$ but CD4-positive T cells have been noted. ${ }^{8-12,17}$ Cytotoxic $\mathrm{T}$ and natural killer cells, demonstrated by T-cell intracytoplasmic antigen-1 and granzyme B, were frequent. ${ }^{9,13,17,18}$ FoxP3, a marker of regulatory $\mathrm{T}$ cells, was seen occasionally. ${ }^{11}$ Interestingly, Epstein-Barr virus (EBV)-encoded RNA ISH positivity has only been seen in one case of LEL-HCC, with corresponding positive EBV sequencing ${ }^{14}$; the vast majority of cases are negative for EBV by ISH and sequencing. ${ }^{6-8,13,18}$

Evidence on LEL-HCC outcomes remains limited and has only been investigated in few retrospective series. A Japanese study, exploring the characteristics and outcomes of resected LEL-HCC $<3 \mathrm{~cm}$ compared 11 LEL-HCC to 116 controls, matched for underlying liver disease. ${ }^{11}$ The recurrence rate after 5 years was $9.1 \%$ for LEL-HCC compared to $47.5 \%$ in the control group $(P<0.01)$, and 5-year survival rate was $100 \%$ versus $68.1 \%$, respectively $(P<0.01)$. Subsequently, Emile et $\mathrm{al}^{13}$ reviewed histology of 162 patients who underwent orthotopic liver transplant for HCC, and identified five LEL-HCC that were further compared to 132 controls. Among LEL-HCC patients, only one had late recurrence and died from disease progression, 8 years after transplant. A recent article from the United States compared eight LELHCC to 18 controls, matched for etiology, age, tumor size, and multifocality. ${ }^{17}$ Although patients with LEL-HCC showed lower rates of local and distant recurrences, the difference did not reach statistical significance, presumably because of lack of statistical power. In a pivotal study, Chan et $\mathrm{al}^{18}$ thoroughly explored LEL-HCC in a retrospective cohort of 409 patients who underwent surgical resection for HCC. A total of 20 LEL-HCC cases $(4.9 \%)$ were identified and compared to $389 \mathrm{HCC}$ cases without significant tumorinfiltrating lymphocytes. LEL-HCC patients, compared to controls, were more likely to be female, and to present with

A

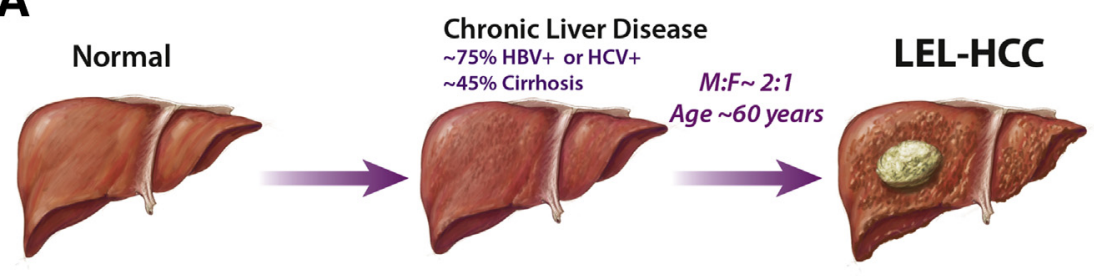

B

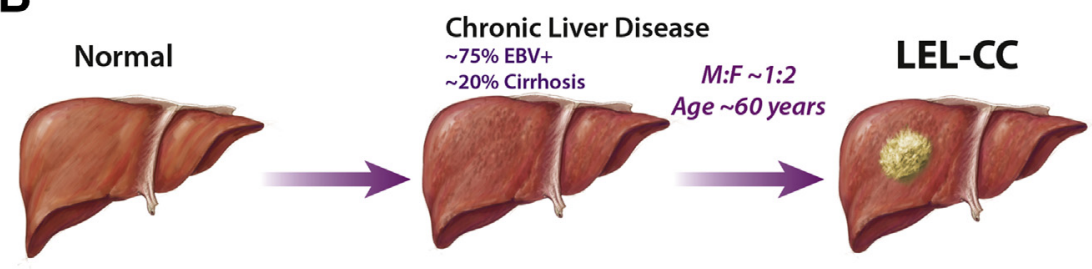

Figure 2 Typical clinical course of hepatic lymphoepithelioma-like carcinoma. A: Lymphoepithelioma-like hepatocellular carcinoma (LEL-HCC) is often the result of chronic liver injury, typically in male patients with viral hepatitis at approximately 60 years. B: Lymphoepithelioma-like cholangiocarcinoma (LEL-CC) is more frequent in female patients at approximately 60 years, from Asia, who are Epstein-Barr virus (EBV) positive. $F$, female; $M$, male; HBV, hepatitis B virus; $\mathrm{HCV}$, hepatitis C virus. Printed with permission from Mount Sinai Health System. 

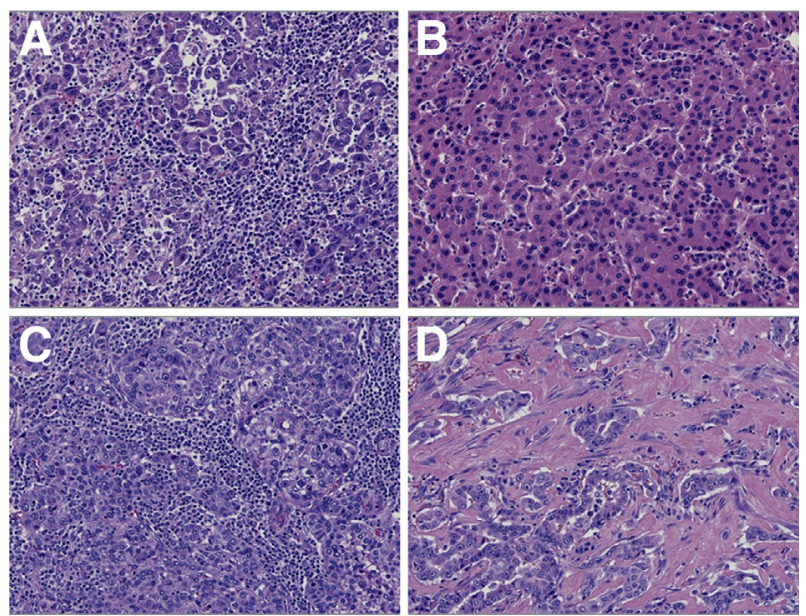

Figure 3 Histology of hepatic lymphoepithelioma-like carcinoma in comparison with liver cancer types. A: Lymphoepithelioma-like hepatocellular carcinoma. Poorly differentiated tumor cells, with abundant discohesive to syncytial, amphophilic cytoplasm, round nuclei with single nucleoli, and mild nuclear pleomorphism, are arranged in sheets. The tumor is extensively infiltrated by small lymphocytes. B: Typical hepatocellular carcinoma. Tumor cells, with abundant eosinophilic cytoplasm and central, round nuclei with single nucleoli, are arranged in thickened trabeculae and rare pseudoglandular forms. C: Lymphoepithelioma-like cholangiocarcinoma. Tumor cells, arranged in sheets rather than glands, with moderate amounts of syncytial, amphophilic cytoplasm and marked tumorinfiltrating lymphocytes. D: Typical cholangiocarcinoma. Poorly formed glands, composed of cells with moderate atypia and high nuclear/cytoplasmic ratio, are surrounded by dense, desmoplastic stroma. Original magnification, $\times 200(\mathbf{A}-\mathbf{D})$.

earlier-stage disease and solitary tumors. Overall survival (5year: $94.1 \%$ versus $63.9 \% ; P=0.007)$ and progression-free survival (5-year: $87.8 \%$ versus $46.6 \% ; P=0.002$ ) rates were higher in LEL-HCC compared to controls. Multivariable analysis showed that LEL-HCC was an independent

Table 3 Immunohistochemical Markers

\begin{tabular}{lrr}
\hline Variable & LEL-HCC $(n=66)$ & LEL-CC $(n=27)$ \\
\hline Pankeratin & $100(19 / 19)$ & $93(13 / 14)$ \\
K19 & $31(4 / 13)$ & $100(16 / 16)$ \\
K7 & $17(1 / 6)$ & $100(21 / 21)$ \\
K20 & $20(1 / 4)$ & $0(0 / 14)$ \\
EMA & $100(1 / 1)$ & $100(6 / 6)$ \\
pCEA $\quad$ & \\
$\quad$ Canalicular pattern & $45(5 / 11)$ & NA \\
$\quad$ Membranous pattern & $0(0 / 9)$ & $22(2 / 9)$ \\
EpCAM & $\mathrm{NA}$ & $100(7 / 7)$ \\
CD56 & $\mathrm{NA}$ & $13(1 / 8)$ \\
C-kit & $\mathrm{NA}$ & $0(0 / 8)$ \\
HepPar-1 & $100(7 / 7)$ & $0(0 / 2)$ \\
p53 & $0(0 / 1)$ & $60(6 / 10)$ \\
p16 & $38(3 / 8)$ & $\mathrm{NA}$ \\
EBER ISH (EBV) & $3(1 / 40)$ & $74(20 / 27)$ \\
\hline
\end{tabular}

Data are given as percentage (number/total).

EBER, EBV-encoded RNA; EBV, Epstein-Barr virus; EMA, epithelial membrane antigen; ISH, in situ hybridization; LEL-CC, lymphoepithelioma-like cholangiocarcinoma; LEL-HCC, lymphoepithelioma-like hepatocellular carcinoma; NA, not available; pCEA, polyclonal carcinoembryonic antigen. prognostic factor for improved overall and progression-free survivals, with an adjusted hazard ratio of 0.12 $(P=0.037)$ and $0.14(P=0.002)$, respectively. Of note, because LEL-HCC diagnosis can only be made by pathological evaluation of the tumor, these studies are by necessity limited to patients who underwent resection or liver transplantation.

Although the genomic landscape of HCC has been comprehensively explored, with identification of the most common genomic aberrations driving hepatocarcinogenesis, ${ }^{21,22}$ LEL-HCC remain largely unstudied from a molecular point of view. Chan et $\mathrm{al}^{18}$ further investigated microsatellite instability, BRAF mutations, and DNA hypermethylation, by comparing 19 LEL-HCC to 38 typical HCC. Microsatellite instability did not differ between the two groups, no BRAF mutations were detected in either tumor type, and no methylation differences, using a panel of four genes of interest (CDKN2B, CDKN2A, RASSF1, and GSTP 1), were observed between LEL-HCC and the typical HCC control group. Recently, a study assessed PD-L1 expression in HCC, in correlation with tumor characteristics and patient outcomes, and found that PD-L1 expression was associated with surrogate markers of aggressiveness, such as $\boldsymbol{\alpha}$-fetoprotein level, satellites, macrovascular and microvascular invasion, and differentiation. ${ }^{19}$ Interestingly, the expression level of PD-L1 within the tumor microenvironment, mostly in infiltrating inflammatory cells, correlated with these markers of poor prognosis, but also with so-called LEL-HCC subtype. This would somehow contradict the assumption that LEL-HCC are associated with better prognosis. Notwithstanding, the study was not designed to specifically address this question and further studies are needed to clarify this point.

\section{LEL-CC}

In the English literature, 27 cases of LEL-CC and one case of extrahepatic LEL-CC have been described (Table 4). Demographically, LEL-CC patients were primarily women, with a median age of 57 years, and the vast majority of cases arose in Asia (92\%) (Figure 2B). Cirrhosis was present in five cases (19\%), and hepatitis B virus and hepatitis $C$ virus were positive in eight (30\%) and two (7\%) patients, respectively. All patients underwent surgical resection, typically for single lesions (86\%), with a median size of $40 \mathrm{~mm}$ (range, 30 to $60 \mathrm{~mm}$ ).

Grossly, the lesions were white-tan, firm, and nonencapsulated, resembling typical iCC. ${ }^{23-36}$ Mean tumor size was $4.5 \pm 2.3 \mathrm{~cm}$ (range, 1.6 to $10.0 \mathrm{~cm}$ ). Histologically, tumors had either two distinct components, LEL-CC and more classic well to moderately differentiated, glandforming cholangiocarcinoma, ${ }^{24-27,29-31,33-35,37}$ or consisted solely of LEL-CC. ${ }^{28,30,32,36,38-40}$ The LEL-CC component, by definition poorly differentiated (grade 3), was composed of neoplastic cells arranged in sheets, cords, 
Table 4 Reported Cases of LEL-CC

No. of

Reference Sex Age, years Race HBV HCV EBV Cirrhosis lesions Size, mm Treatment FU, months Outcomes

\begin{tabular}{|c|c|c|c|c|c|c|c|c|c|c|c|c|}
\hline Adachi et $a^{23}$ & M & 64 & Asian & - & - & - & - & 1 & 52 & LR & 3 & AWOD \\
\hline \multirow[t]{2}{*}{ Chen et $\mathrm{al}^{24}$} & $\mathrm{~F}$ & 67 & Asian & - & - & + & - & 1 & 50 & LR & $<1$ & POD \\
\hline & M & 41 & Asian & + & - & - & + & 1 & 30 & $\mathrm{LR}$ & 8 & AWOD \\
\hline Henderson-Jackson et $\mathrm{al}^{25}$ & $\mathrm{~F}$ & 63 & Asian & - & - & + & - & 1 & 40 & $\mathrm{LR}$ & 6 & AWOD \\
\hline Hsu et $\mathrm{al}^{26}$ & $\mathrm{~F}$ & 47 & Asian & - & - & + & - & 2 & 120 & LR & 48 & DOD \\
\hline Huang et $\mathrm{al}^{27}$ & $\mathrm{~F}$ & 60 & Asian & - & - & + & - & 1 & 35 & NA & 24 & AWOD \\
\hline Hur et $\mathrm{al}^{28}$ & $\mathrm{~F}$ & 57 & Asian & - & - & - & - & 1 & 20 & LR & 60 & AWOD \\
\hline Ishida et $\mathrm{al}^{29 *}$ & $M$ & 68 & Asian & - & + & - & - & 2 & 30 & $\mathrm{PD}$ & 5 & AWOD \\
\hline \multirow[t]{4}{*}{ Jeng et $\mathrm{al}^{30}$} & $M$ & 42 & Asian & - & - & + & - & 1 & 30 & LR & 84 & AWOD \\
\hline & $\mathrm{F}$ & 67 & Asian & - & - & + & - & 1 & 30 & LR & 7 & AWOD \\
\hline & M & 50 & Asian & - & - & + & - & 1 & 40 & $\mathrm{LR}$ & 16 & AWOD \\
\hline & $\mathrm{F}$ & 50 & Asian & - & - & + & - & 1 & 40 & LR & 2 & AWOD \\
\hline Kim et $\mathrm{al}^{31}$ & M & 64 & Asian & - & + & - & + & 1 & 20 & LR & $\mathrm{NA}$ & NA \\
\hline Labgaa et $\mathrm{al}^{32}$ & $M$ & 58 & Asian & + & - & + & - & 1 & 22 & LR & 61 & AWOD \\
\hline $\operatorname{Lee}^{33}$ & M & 79 & Asian & + & - & - & + & 2 & 35 & LR & 54 & AWOD \\
\hline Liao et $\mathrm{al}^{34}$ & $\mathrm{~F}$ & 35 & NA & + & - & + & + & 1 & 16 & LR & NA & NA \\
\hline Ortiz et $\mathrm{al}^{35}$ & $\mathrm{~F}$ & 19 & White & - & - & + & - & 1 & 55 & LR & 44 & DOD \\
\hline Szekely $^{36}$ & M & 61 & NA & - & - & - & - & 1 & 60 & NA & 11 & AWOD \\
\hline Vortmeyer et $\mathrm{al}^{37}$ & $\mathrm{~F}$ & 71 & White & - & - & + & - & 2 & 50 & NA & 36 & AWD \\
\hline \multirow[t]{7}{*}{ Chan et $\mathrm{al}^{38}$} & $\mathrm{~F}$ & 53 & Asian & + & - & + & + & 1 & 16 & LR & 165 & AWOD \\
\hline & $\mathrm{F}$ & 40 & Asian & + & - & + & - & 1 & 75 & LR & 56 & AWD \\
\hline & $\mathrm{F}$ & 57 & Asian & - & - & + & - & 1 & 71 & $\mathrm{LR}$ & 128 & AWOD \\
\hline & $\mathrm{F}$ & 56 & Asian & - & - & + & - & 1 & 60 & LR & 69 & DOD \\
\hline & $\mathrm{F}$ & 59 & Asian & + & - & + & - & 1 & 60 & LR & 72 & AWOD \\
\hline & $\mathrm{F}$ & 45 & Asian & - & - & + & - & 1 & 30 & LR & 71 & AWD \\
\hline & $\mathrm{F}$ & 57 & Asian & - & - & + & - & 1 & 30 & LR & 58 & AWOD \\
\hline Aosasa et $\mathrm{al}^{39}$ & $\mathrm{~F}$ & 65 & NA & - & + & - & - & 1 & 64 & LR & 20 & AWOD \\
\hline Min et $\mathrm{al}^{40}$ & M & 46 & Asian & + & - & + & - & 1 & 27 & LR & 84 & AWD \\
\hline
\end{tabular}

*Extrahepatic LEL-CC.

F, female; M, male; +, positive; -, negative; AWD, alive with disease; AWOD, alive without disease; DOD, died of disease; EBV, Epstein-Barr virus; FU, follow-up; HBV, hepatitis B virus; HCV, hepatitis C virus; LEL-CC, lymphoepithelioma-like cholangiocarcinoma; LR, liver resection; NA, not available; PD, pancreaticoduodenectomy; POD, postoperative death.

or poorly formed glands, surrounded and infiltrated by a distinctive dense lymphoid population. The neoplastic cells are also enlarged, with abundant syncytial cytoplasm, vesicular chromatin, and prominent nucleoli (Figure 3C), in comparison with typical iCC (Figure 3D). The World Health Organization recognizes LELC as a variant of iCC, but does not further define the density of the lymphocytic infiltrate required for diagnosis. ${ }^{20}$

A summary of immunohistochemical expression patterns in the carcinomatous component is shown in Table 3. The neoplastic cells express pankeratin (eg, AE1/ AE3) ${ }^{23-25,27-29,32,33,35-38}$ and epithelial membrane antigen, ${ }^{23,27,28,33,36,37}$ biliary-type keratins K19 $9^{24,25,29,31,32,35,39}$ and $\mathrm{K} 7,{ }^{18,23-27,29,30,32,33}$ and biliary lineage markers EpCAM $^{38}$ and CA19-9. ${ }^{27,29}$ Expression of stem/progenitor cell markers CD56, CD133, and C-KIT is rare. ${ }^{38} \mathrm{CD} 133$ may show luminal, but not membranous, positivity. ${ }^{38}$ More than half of tumors show a mutation-associated p53 immunohistochemistry pattern. ${ }^{29,33,35,38}$ Tumors are generally negative for polyclonal carcinoembryonic antigen, ${ }^{23-25,27,31,33,36,37}$ with no canalicular staining pattern, K20, ${ }^{23-25,27-30,33,36}$ and HepPar- $1 .^{25,28,29,33,34,38}$ The tumor-infiltrating lymphocytes are predominantly CD3positive $\mathrm{T}$ cells, ${ }^{23-25,27,29,33-36}$ with focal CD20-positive B cells ${ }^{23-25,27,29,34-37}$ and CD138-positive plasma cells. ${ }^{29}$ EBV latent membrane protein 1 immunohistochemistry is negative $^{23,34,38}$; however, EBV-encoded RNA ISH positivity is reported in $74 \%$ of cases. When sequencing was performed, 57\% of cases identified EBV. ${ }^{24,26,27,31,36,37}$ The high prevalence of EBV in these tumors is of particular interest, may indicate a causal role of the virus in tumorigenesis, and could trigger an immune response leading to the characteristic dense lymphocytic infiltrate seen on histology and better survival.

Similar to LEL-HCC, data on LEL-CC outcomes are limited, with only one available retrospective series; this study compared seven LEL-CC with 11 stage-matched iCC. ${ }^{38}$ Although no significant difference was highlighted for disease-free survival (5-year: $57.1 \%$ versus $11.7 \%$; $P=0.1$ ), LEL-CC patients had a significantly higher overall survival rate than iCC patients (5-year: 100\% versus $13.2 \% ; P=0.003)$. Because pathological evaluation of the tumor is required to diagnose LEL-CC, this study is necessarily limited to patients who underwent surgery. 
Molecular studies of LEL-CC are also scarce. Chan et al ${ }^{38}$ assessed genomic readouts of the tumors, including mutations of $E G F R$ and $K R A S$, and DNA methylation status of 20 genes. Among these 20 genes, only CRBPI and CRBPIV were significantly hypermethylated in LEL-CC, compared to iCC. Regarding mutational analysis, there was no statistically significant difference in EGFR and KRAS mutations.

\section{Future Prospects}

Although hepatic LELC remains poorly understood, preliminary data suggest that it is a specific subtype of both HCC and iCC, with distinctive epidemiological, pathological, molecular characteristics and superior outcomes. More important, LELC represents a unique model of immune response in liver cancer. Hence, a deeper understanding of this entity may provide valuable insights for therapeutic strategies, and LELC should be the target of future clinical and translational studies, with a multidisciplinary approach.

The current level of evidence on LELC is solely based on case reports and small retrospective series. Thus, larger, ideally prospective studies are required to study the impact of LELC, if any, on prognosis. Furthermore, our understanding of this disease is limited to early-stage cancers, as all reported patients underwent either liver resection or liver transplant. Hence, future prospective studies including both surgical specimens and biopsies would be informative to elucidate the whole spectrum of this disease. There is a need to better characterize LELC patients in terms of prevalence and demographics, but also in terms of relationship to underlying liver disease, comorbidities, and ethnicity. Although LELHCC patients do not seem to notably differ from typical HCC patients, LEL-CC patients showed striking differences compared to iCC patients in such factors as EBV prevalence and sex (Figure 2). This finding deserves to be further explored to understand whether EBV is directly involved in the development of LEL-CC, or if it offers a protective effect by enhancing the immune response against the tumor. Likewise, a broader analysis of potential viral integrations in LEL$\mathrm{HCC}$ would be of great interest. As an example, a recent study observed for the first time the integration of adeno-associated virus type 2 in a subset of HCC $[11 / 193(6 \%)],{ }^{41}$ but the authors did not specify whether adeno-associated virus type 2 integration was associated with immune infiltrate.

Clinically, validation that LELC patients have better prognosis compared to patients with typical liver cancer is needed, which will require larger studies that are ideally prospectively designed.

There is a need to find a consensus on the definition of liver LELC. Although Wada et $\mathrm{al}^{11}$ proposed a cutoff of $>100$ tumor-infiltrating lymphocytes per 10 high-power fields, the World Health Organization did not establish such clear metrics for diagnosis. Investigating new immunohistochemical markers would also be pertinent, as underlined by the study of Calderaro et $\mathrm{al}^{19}$ that assessed
PD-L1 expression in HCC. This of particular interest because PD-L1 expression is suggested to predict response to PD1/PD-L1 targeting therapies. ${ }^{42}$ The application of immunotherapy for cancer treatment is rapidly accelerating and is being studied in liver cancer with ongoing trials (NCT02576509). Proper lineage classification of liver neoplasms, including LELC, is critical for further study and generation of meaningful results.

Translational studies with comprehensive molecular analyses of these tumors would presumably clarify the underlying mechanism(s) driving the immune response in these patients. Assessing for correlation between liver LELC and tumors that belong to molecular subclass related to immune response, such as the interferon subclass in HCC, would be opportune. ${ }^{43}$ Current data have only integrated a small number of genes for mutation or methylation analyses. In addition, the interrogated genes were not necessarily those known to be most commonly mutated in liver cancer. Therefore, further study comparing liver LELC and their typical counterparts, in term of mutations, copy number alterations, and methylation changes, are needed.

\section{Acknowledgments}

We thank Christopher Smith for his design support with Figure 2.

I.L. and A.S. wrote the article; I.L., A.S., and S.C.W. designed the concept, reviewed the literature, and revised the article.

\section{References}

1. Torre LA, Bray F, Siegel RL, Ferlay J, Lortet-Tieulent J, Jemal A: Global cancer statistics, 2012. CA Cancer J Clin 2015, 65:87-108

2. DeSantis CE, Lin CC, Mariotto AB, Siegel RL, Stein KD, Kramer JL, Alteri R, Robbins AS, Jemal A: Cancer treatment and survivorship statistics, 2014. CA Cancer J Clin 2014, 64:252-271

3. Murray CJ, Vos T, Lozano R, Naghavi M, Flaxman AD, Michaud C, et al: Disability-adjusted life years (DALYs) for 291 diseases and injuries in 21 regions, 1990-2010: a systematic analysis for the Global Burden of Disease Study 2010. Lancet 2012, 380:2197-2223

4. Llovet JM, Villanueva A, Lachenmayer A, Finn RS: Advances in targeted therapies for hepatocellular carcinoma in the genomic era. Nat Rev Clin Oncol 2015, 12:436

5. Solinas A, Calvisi DF: Lessons from rare tumors: hepatic lymphoepitheliomalike carcinomas. World J Gastroenterol 2015, 21:3472-3479

6. An SL, Liu LG, Zheng YL, Rong WQ, Wu F, Wang LM, Feng L, Liu FQ, Tian F, Wu JX: Primary lymphoepithelioma-like hepatocellular carcinoma: report of a locally advanced case and review of literature. Int J Clin Exp Pathol 2015, 8:3282-3287

7. Chen CJ, Jeng LB, Huang SF: Lymphoepithelioma-like hepatocellular carcinoma. Chang Gung Med J 2007, 30:172-177

8. Cacciato Insilla A, Faviana P, Pollina LE, De Simone P, Coletti L, Filipponi F, Campani D: Lymphoepithelioma-like hepatocellular carcinoma: case report and review of the literature. World J Gastroenterol 2015, 21:10468-10474

9. Shinoda M, Kadota Y, Tsujikawa H, Masugi Y, Itano O, Ueno A, Mihara K, Hibi T, Abe Y, Yagi H, Kitago M, Kawachi S, Tanimoto A, 
Sakamoto M, Tanabe M, Kitagawa Y: Lymphoepithelioma-like hepatocellular carcinoma: a case report and a review of the literature. World J Surg Oncol 2013, 11:97

10. Wei J, Liu Q, Wang C, Yu S: Lymphoepithelioma-like hepatocellular carcinoma without Epstein-Barr virus infection: a case report and a review of the literature. Indian J Pathol Microbiol 2015, 58:550-553

11. Wada Y, Nakashima O, Kutami R, Yamamoto O, Kojiro M: Clinicopathological study on hepatocellular carcinoma with lymphocytic infiltration. Hepatology 1998, 27:407-414

12. Park HS, Jang KY, Kim YK, Cho BH, Moon WS: Hepatocellular carcinoma with massive lymphoid infiltration: a regressing phenomenon? Pathol Res Pract 2009, 205:648-652

13. Emile JF, Adam R, Sebagh M, Marchadier E, Falissard B, Dussaix E, Bismuth H, Reynes M: Hepatocellular carcinoma with lymphoid stroma: a tumour with good prognosis after liver transplantation. Histopathology 2000, 37:523-529

14. Si MW, Thorson JA, Lauwers GY, DalCin P, Furman J: Hepatocellular lymphoepithelioma-like carcinoma associated with epstein barr virus: a hitherto unrecognized entity. Diagn Mol Pathol 2004, 13:183-189

15. Nemolato S, Fanni D, Naccarato AG, Ravarino A, Bevilacqua G, Faa G: Lymphoepithelioma-like hepatocellular carcinoma: a case report and a review of the literature. World J Gastroenterol 2008, 14:4694-4696

16. Shirabe K, Matsumata T, Maeda T, Sadanaga N, Kuwano H, Sugimachi K: A long-term surviving patient with hepatocellular carcinoma including lymphocytes infiltration: a clinicopathological study. Hepatogastroenterology 1995, 42:996-1001

17. Patel KR, Liu TC, Vaccharajani N, Chapman WC, Brunt EM: Characterization of inflammatory (lymphoepithelioma-like) hepatocellular carcinoma: a study of 8 cases. Arch Pathol Lab Med 2014, 138: 1193-1202

18. Chan AW, Tong JH, Pan Y, Chan SL, Wong GL, Wong VW, Lai PB, To KF: Lymphoepithelioma-like hepatocellular carcinoma: an uncommon variant of hepatocellular carcinoma with favorable outcome. Am J Surg Pathol 2015, 39:304-312

19. Calderaro J, Rousseau B, Amaddeo G, Mercey M, Charpy C, Costentin C, Luciani A, Zafrani ES, Laurent A, Azoulay D, Lafdil F, Pawlotsky JM: PD-L1 expression in hepatocellular carcinoma: relationship with clinical and pathological features. Hepatology 2016, 64:2038-2046

20. Bosman FT, World Health Organization, International Agency for Research on Cancer: WHO Classification of Tumours of the Digestive System. ed 4. Lyon: International Agency for Research on Cancer, 2010

21. Schulze K, Imbeaud S, Letouze E, Alexandrov LB, Calderaro J, Rebouissou S, Couchy G, Meiller C, Shinde J, Soysouvanh F, Calatayud AL, Pinyol R, Pelletier L, Balabaud C, Laurent A, Blanc JF, Mazzaferro V, Calvo F, Villanueva A, Nault JC, Bioulac-Sage P, Stratton MR, Llovet JM, Zucman-Rossi J: Exome sequencing of hepatocellular carcinomas identifies new mutational signatures and potential therapeutic targets. Nat Genet 2015, 47:505-511

22. Totoki Y, Tatsuno K, Covington KR, Ueda H, Creighton CJ, Kato M, et al: Trans-ancestry mutational landscape of hepatocellular carcinoma genomes. Nat Genet 2014, 46:1267-1273

23. Adachi S, Morimoto O, Kobayashi T: Lymphoepithelioma-like cholangiocarcinoma not associated with EBV. Pathol Int 2008, 58:69-74

24. Chen TC, Ng KF, Kuo T: Intrahepatic cholangiocarcinoma with lymphoepithelioma-like component. Mod Pathol 2001, 14:527-532

25. Henderson-Jackson E, Nasir NA, Hakam A, Nasir A, Coppola D: Primary mixed lymphoepithelioma-like carcinoma and intra-hepatic cholangiocarcinoma: a case report and review of literature. Int J Clin Exp Pathol 2010, 3:736-741

26. Hsu HC, Chen CC, Huang GT, Lee PH: Clonal Epstein-Barr virus associated cholangiocarcinoma with lymphoepithelioma-like component. Hum Pathol 1996, 27:848-850
27. Huang Y, Tsung JS, Lin CW, Cheng TY: Intrahepatic cholangiocarcinoma with lymphoepithelioma-like carcinoma component. Ann Clin Lab Sci 2004, 34:476-480

28. Hur YH, Kim HH, Koh YS, Seoung JS, Cho CK: Lymphoepitheliomalike cholangiocarcinoma not associated with Epstein-Barr virus. ANZ J Surg 2011, 81:652-653

29. Ishida M, Mori T, Shiomi H, Naka S, Tsujikawa T, Andoh A, Saito Y, Kurumi Y, Kojima F, Hotta M, Tani T, Fujiyama Y, Okabe H: NonEpstein-Barr virus associated lymphoepithelioma-like carcinoma of the inferior common bile duct. World J Gastrointest Oncol 2011, 3:111-115

30. Jeng YM, Chen CL, Hsu HC: Lymphoepithelioma-like cholangiocarcinoma: an Epstein-Barr virus-associated tumor. Am J Surg Pathol 2001, 25:516-520

31. Kim YB, Park YN, Han JY, Hong KC, Hwang TS: Biliary lymphoepithelioma-like carcinoma not associated with Epstein-Barr virus. Arch Pathol Lab Med 1999, 123:441-443

32. Labgaa I, Hiotis S, Ward SC: Lymphoepithelioma-like cholangiocarcinoma: a rare finding with good outcomes. J Clin Gastroenterol 2016, 50:268

33. Lee W: Intrahepatic lymphoepithelioma-like cholangiocarcinoma not associated with epstein-barr virus: a case report. Case Rep Oncol 2011, 4:68-73

34. Liao TC, Liu CA, Chiu NC, Yeh YC, Chiou YY: Lymphoepitheliomalike cholangiocarcinoma: a mimic of hepatocellular carcinoma on imaging features. World J Gastroenterol 2015, 21:4089-4095

35. Ortiz MR, Garijo G, Adrados M, Lopez-Bonet E, Acero D, Bernado L: Epstein-Barr virus-associated cholangiocarcinoma with lymphoepithelioma-like component. Int J Surg Pathol 2000, 8: $347-351$

36. Szekely E: Lymphoepithelioma-like cholangiocarcinoma (LELC) not associated with Epstein-Barr virus. Am J Surg Pathol 2001, 25: 1464-1466

37. Vortmeyer AO, Kingma DW, Fenton RG, Curti BD, Jaffe ES, Duray PH: Hepatobiliary lymphoepithelioma-like carcinoma associated with Epstein-Barr virus. Am J Clin Pathol 1998, 109:90-95

38. Chan AW, Tong JH, Sung MY, Lai PB, To KF: Epstein-Barr virusassociated lymphoepithelioma-like cholangiocarcinoma: a rare variant of intrahepatic cholangiocarcinoma with favourable outcome. Histopathology 2014, 65:674-683

39. Aosasa S, Maejima T, Kimura A, Nishiyama K, Edo H, Shinmoto H, Kaji T, Ogata S, Hatsuse $\mathrm{K}$, Hase $\mathrm{K}$, Yamamoto $\mathrm{J}$ : Intrahepatic cholangiocarcinoma with lymphoepithelioma-like carcinoma components not associated with Epstein-Barr virus: report of a case. Int Surg 2015, 100:689-695

40. Min HS, Shin E, Jang JJ: [Carcinoma with predominant lymphoid stroma in hepatobiliary system: report of 2 cases] Korean. Korean J Hepatol 2007, 13:222-227

41. Nault JC, Datta S, Imbeaud S, Franconi A, Mallet M, Couchy G, Letouze E, Pilati C, Verret B, Blanc JF, Balabaud C, Calderaro J, Laurent A, Letexier M, Bioulac-Sage P, Calvo F, Zucman-Rossi J: Recurrent AAV2-related insertional mutagenesis in human hepatocellular carcinomas. Nat Genet 2015, 47:1187-1193

42. Patel SP, Kurzrock R: PD-L1 expression as a predictive biomarker in cancer immunotherapy. Mol Cancer Ther 2015, 14:847-856

43. Chiang DY, Villanueva A, Hoshida Y, Peix J, Newell P, Minguez B, LeBlanc AC, Donovan DJ, Thung SN, Sole M, Tovar V, Alsinet C, Ramos AH, Barretina J, Roayaie S, Schwartz M, Waxman S, Bruix J, Mazzaferro V, Ligon AH, Najfeld V, Friedman SL, Sellers WR, Meyerson M, Llovet JM: Focal gains of VEGFA and molecular classification of hepatocellular carcinoma. Cancer Res 2008, 68: 6779-6788 